\title{
واقع تطبيق مبادئ ميثاق حوكمة الشركات في الجزائر: دراسة حالة مؤسسة إدوغ بعنابة، الجزائر
}

\section{The Reality of Applying Corporate Governance}

\section{Charter Principles in Algeria}

\section{- A Case Study of the Idoug Company in Annaba- Algeria}

Mr. ZAAICH MOHAMED

PhD. Student/ Baji Mukhtar University/ Algeria zaaich25@hotmail.com

Dr. KHIARI ZAHIA

Senior Lecturer "A"/ Baji Mukhtar University/ Algeria khiariz2007@yahoo.fr

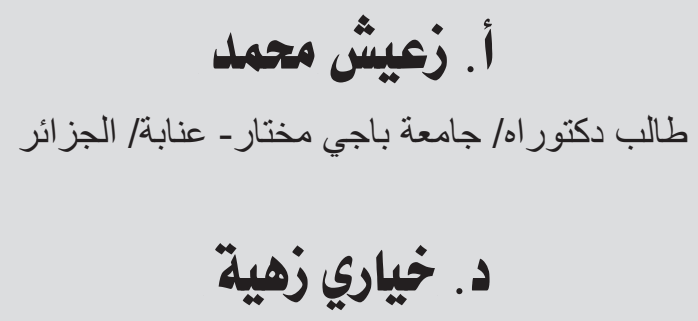

أ. زميش محمد

طالب دكتور اه/ جامعة باجي مختار - عنابة/ الجزائر مئر

د. خياري زهية

أستاذ محاضر" "أ"/ جامعة باجي مختار -عنابة/ الجزائر
Received: 7/ 9/ 2018, Accepted: 19/ 11/ 2018 DOI:

http: //journals.qou.edu/index.php/eqtsadia

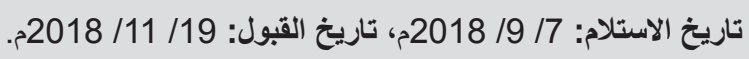

E - ISSN: 2410 - 3349

P - ISSN: 2313 - 7592 


\section{مقدمة: - مقام}

توالت الأزمات الاقتصادية التي عصفت بكبرى اقتصاديات

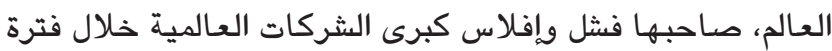

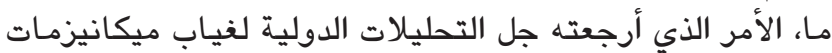

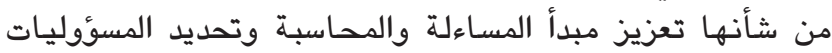

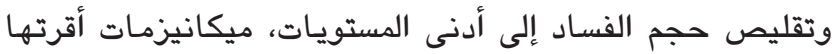

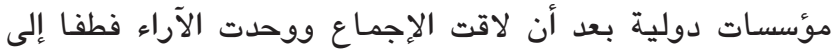

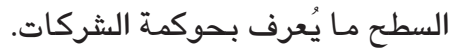

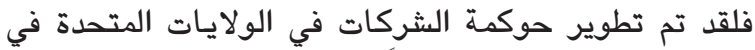

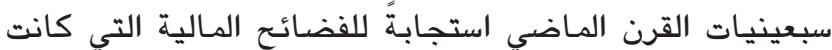

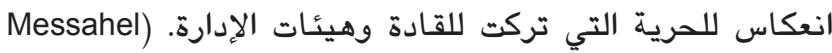

(Sassia, 2017 : 104

وتعبّر حوكمة الثركات عن القواعد التي تحدد كيفية اتخاذ

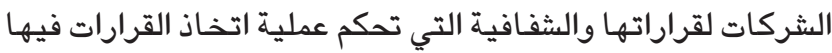

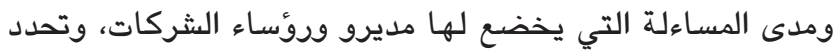

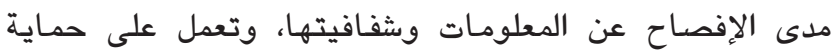

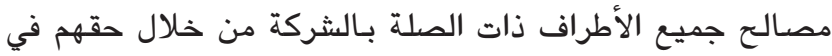

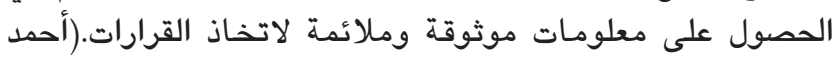

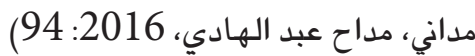

فحوكمة الثركات تستند إلى مبادئ الشفافية والاستقلال الثاد والمساءلة وتهدف إلى تحفيز تبني السلوكيات. Abdelkader) Rachedi, Mohamed Maarif, Mohamed Benhamida, 2014 : 101)

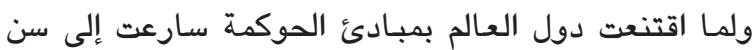

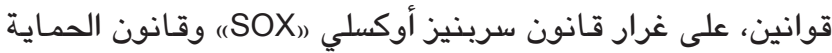

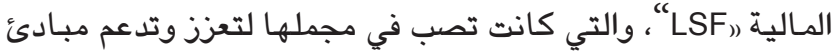

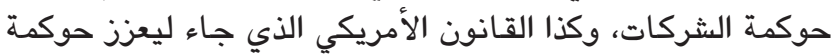

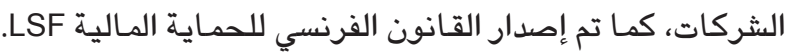

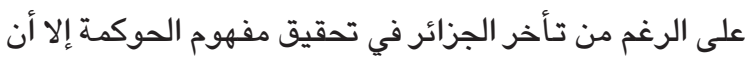

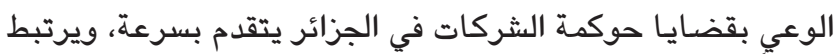
ارتباطًا وثيقًا بمسألة الانتقال إلى اقتصاد فئاد سوق حديثة وفعالة. (Meziani Henen, Chelil Abdellatif, 2014 : 170)

فالجزائر، على غرار العديد من الدول، قامت بإصدار ميثاق

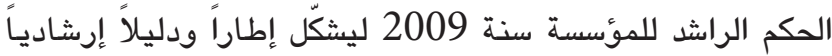

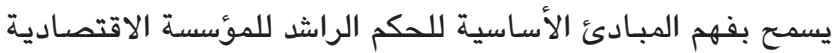

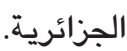

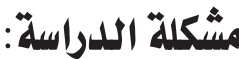

لطالها عانت المؤسسات الاقتصادية في الجزائر من مستويات

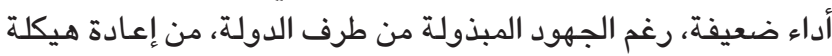

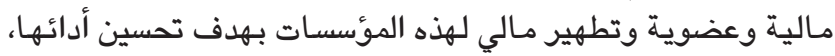

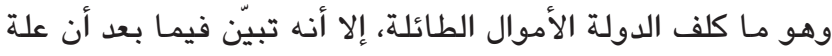

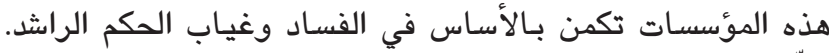

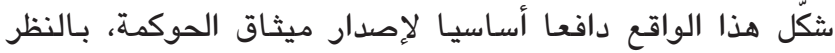

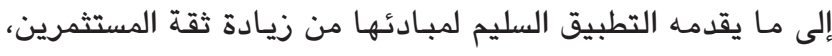

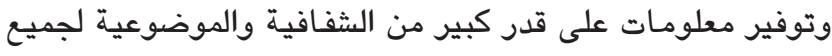

تهدف الدراسة إلى التعريف بميثاق حوكمة الثركات الصادر

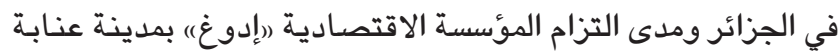

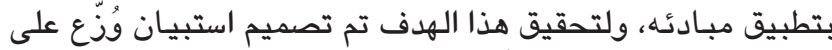

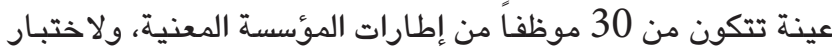

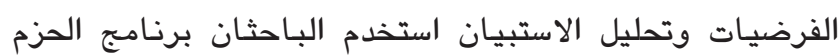

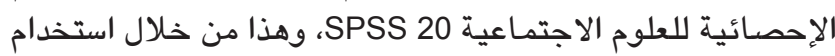

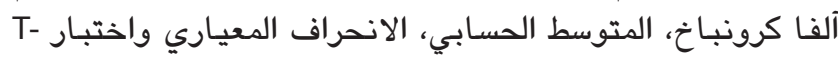
Test

توصلت الدراسة إلى أن المؤسسة تطبق مبادئ ميثاق حوكمة الدمان

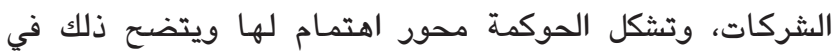

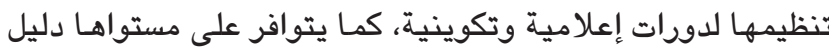

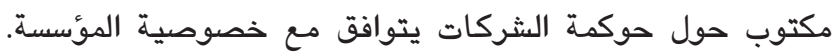

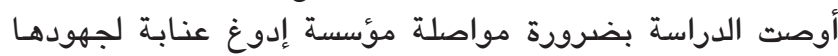

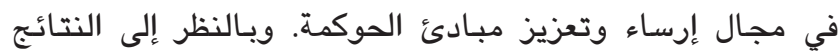

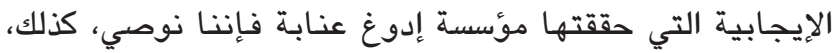

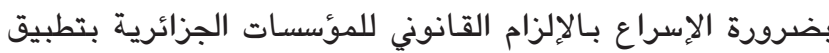
مبادئ الحوكمة، والعمل على توفير الإطار المؤسسي والقانوني الإني

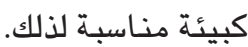

الكلمات المفتاحية: ميثاق حوكمة الشركات، مبادئ الحوكمة، مؤسسة إدوغ ان العان

\section{Abstract:}

This study aims at introducing the corporate governance charter issued in Algeria and the extent of Idoug Company commitment to its principles. To achieve this goal, a questionnaire was distributed to a sample of 30 employees working in the company in order to test the hypotheses and analyse the questionnaire via SPSS version 20. This is done by using alpha- cronbach, arithmetic mean, standard deviation and $T$-Test for one sample. The study concluded that the company applies the principles of the corporate governance charter. The study also proved that Idoug is very interested in governance as evidenced by its organization of training courses and the availability of a written guide on corporate governance in line with the company's specificity. The study recommended that the company should continue its efforts in establishing and strengthening the principles of governance. In view of the positive results achieved by the Idoug Company, we recommend that the legal obligation of Algerian companies to implement the principles of governance should be accelerated and that the institutional and legal framework should be provided as an appropriate environment.

Keywords: Corporate Governance Charter, Governance Principles, Idoug Company. 


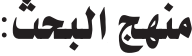

لتحقيق أهداف الدراسة تم الاعتماد على المنهج الوصفي توكي

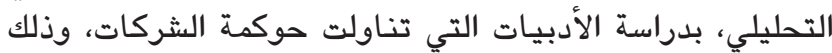

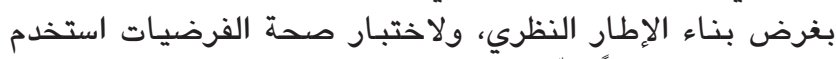

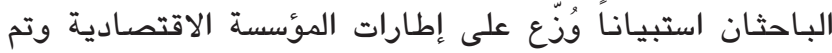

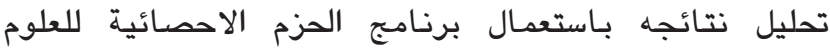

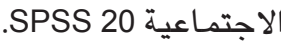

\section{أولا: الإطار النظري لحوكمة الشركات:}

\section{تعريف حوكمة الشركات}

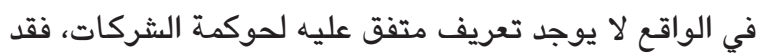

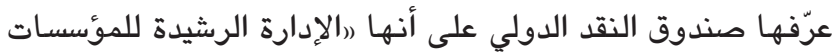

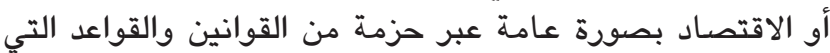

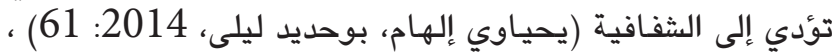

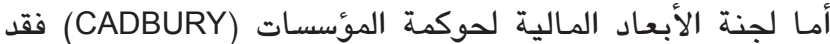
عرفت حوكمة الثركات بأنها " بنظام بمقتضاه التواه تدار المؤسسات

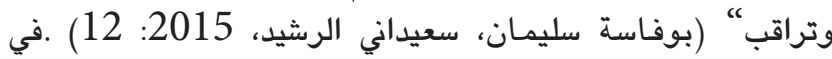

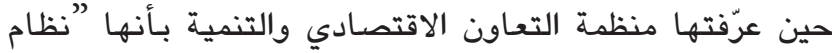

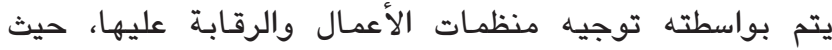

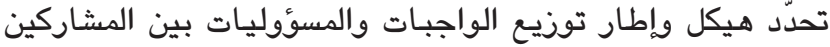

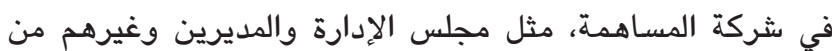

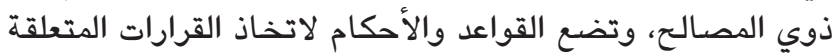

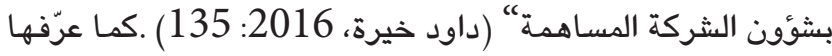

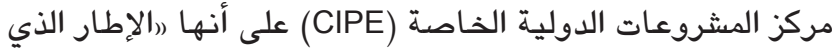

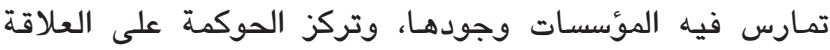

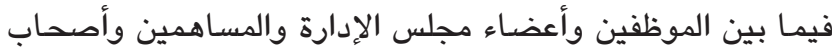

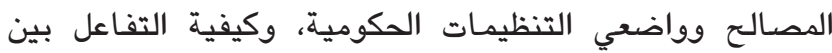

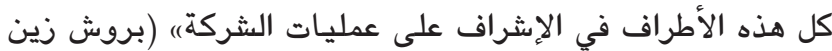

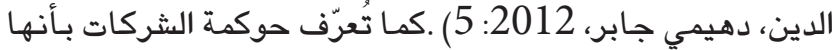

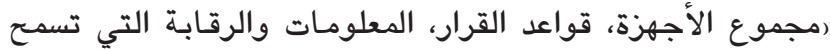

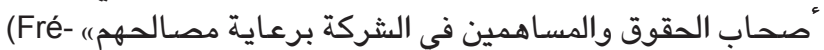
déric Bernard, Rémi Gayraud, Laurent Rousseau, 2013 (56. وعرفتها منظمة التعاون الاقتصادي والتنمية بأنها العلاقة

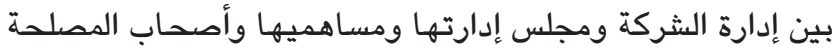

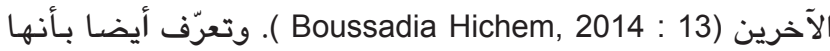

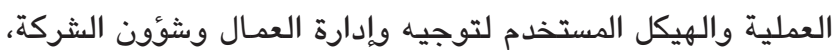

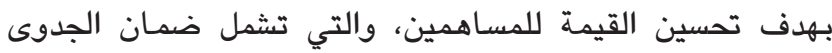

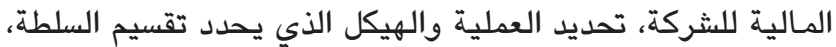

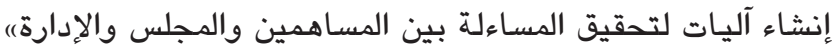
(Rich Hayes, Roger Dassen, Arnold Schilder, Philip Wallage, (595) : 2005. فحوكمة الثركات تشمل مجموع الآليات التنظيمية والتي تهدف إلى تحديد الصلاحيات والتأثير في قرارات المسييرين. (Belabdelli Abdallah, 2017 : 688)

أما المشرّع الجزائري فقد عرّفها بأنها رتلك العملية الإرادية

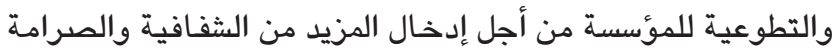

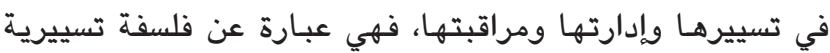

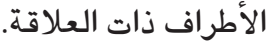

يهدف موضوع هذا الميثاق إلى وضع وسيلة عملية وأداة

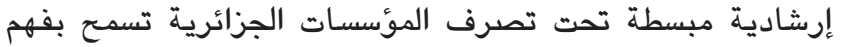

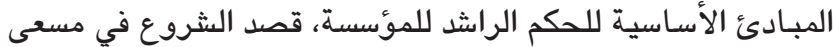

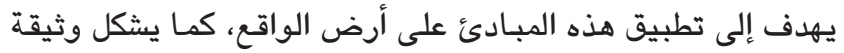

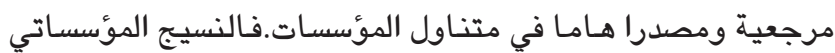

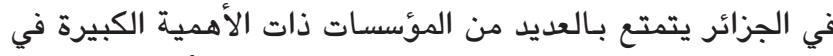

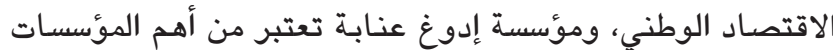

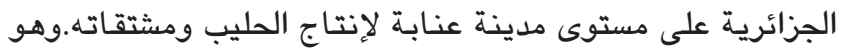
ما يقودنا إلى صياغة إشكالية الدراسة على النحو التالي:

ما هو واقع تطبيق مبادئ ميثاق حوكمة الشركات في مؤسسة إدوغ عنابـة هو واقع تطبي

يتفرع عن التساؤل الرئيسي سؤالان فرعيان: ما هو ميثاق حوكمة الثركات وماهي مبادئه؟

ما مدى التزام مؤسسة إدوغ بتطبيق مبادئ ميثاق

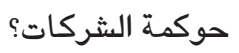

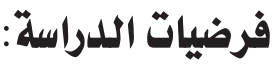

للإجابة عن إشكالية الدراسة تمت صياغة الفرضية الرئيسية

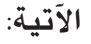

لا تطبق مؤسسة إدوغ عنابة مبادئ ميثاق حوكمة

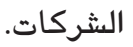

يتفرع عن الفرضية الرئيسية الفرضيات الفرعية التالية:

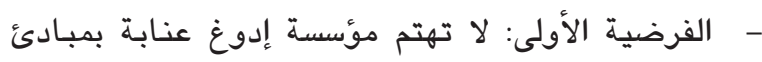

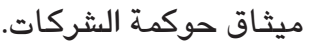
- - الفرضية الثانية: لا تطبق مؤسسة إدوغ عنابة مبلئي الإنصاف والشفافية. - الفرضية الثالثة: لا تطبق مؤسسة إدوغ عنابة مبدئي

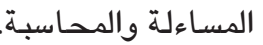

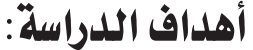

تهنف هذه الدراسة إلى التعريف بميثاق حوكمة الثركات إندات

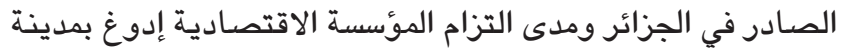

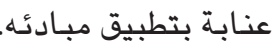

\section{أهمية اللدراسة:}

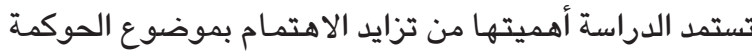

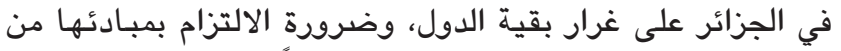

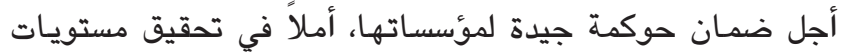
أداء أفضل، ولعل الحركات الإصلاحية التي عرفتها الجزائر منذ فئن

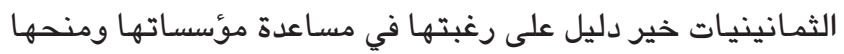
فرصة البقاء والاستقرار.

وتوّجت الجهود المبذولة في هذا الإطار بإصدار ميثاق الحكم الراشد الذي يطمح إلى إعطاء انطلاقة جديدة لترقية الحوكمة ضمن الإن إصنا بُعد شامل ودائم للمؤسسة الجزائرية. 
للمؤسسة الجزائرية، قام بتحريره فريق العمل المكلف (GOAL) بمساهمة جمعية حلقة العمل والتفكير حول المؤسسة (CARE)

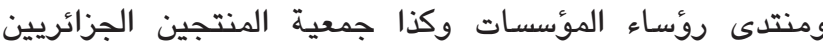

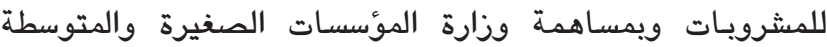
code algérien de gouvernance) والصناعة التقليدية في 27 : وقد تم الاستناد بشكل أساسي

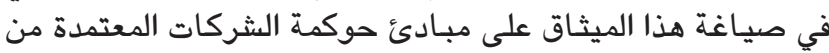

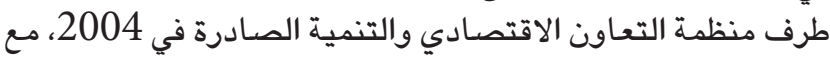

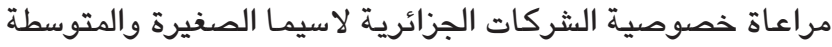
باعتبارهـا تشكل شريحة واسعة من مجتمع الأعمال الجزائري.

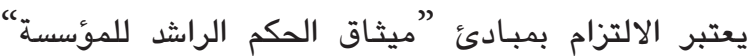

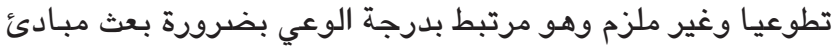

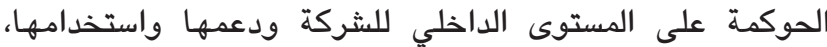
ويتضمن الميثاق جزئين: (ميثاق الحكم الراشد للمؤسسة في الجزائر،

(17:2009

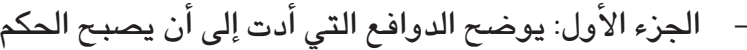

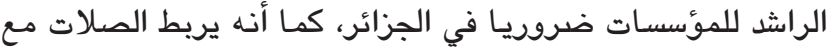

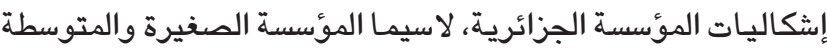

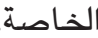

- - الجزء الثاني: يتطرق إلى المقاييس الأساسية التي ينبني

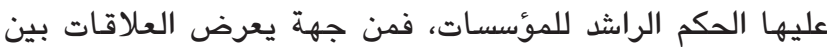

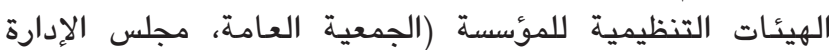

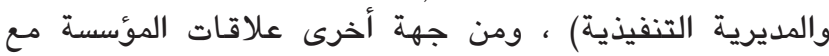

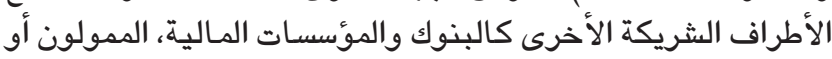
الإدارة، بالإضـافة إلى نوعية نثر المعلومات وأسات وأساليب نقل الملكية.

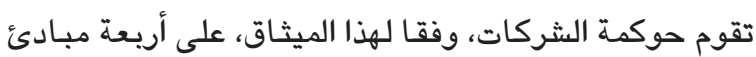

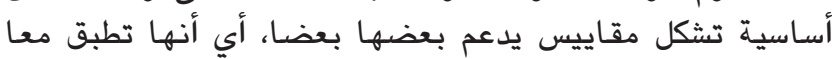

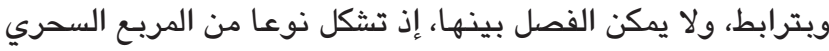

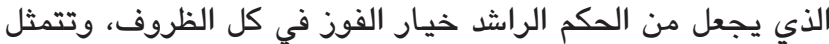
هذه المبادئ فيما يلي: (ميثاق الحكم الراشد للمؤسسة في الجزائر،

(66 2009

- الإنصاف: الحقوق والواجبات الخاصة بالأطراف الثريكة، وكذا الامتيازات والالتزامات المرتبطة بها يجب أن توزع الأطراف

بهورة منصفة

- الثفافية: الحقوق والواجبات، وكنا الصلاحيات

والمسؤوليات المترتبة عن ذلك، يجب أن تكون واضحة وكرات وليحة

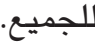

- المساءلة: مسؤولية كل طرف محددة على حدى بواسطة

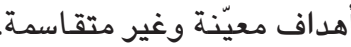
- المحاسبة: كل طرف شريك يكون محاسبا أمام طرف آخر

$$
\text { عن الشيء الذي هو مسؤول عنه. }
$$

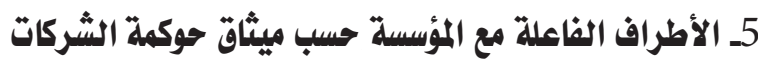
إن موضوع حوكمة الشركات حسب ميثاق الحكم الراشد

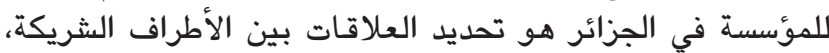
حيث يميّز في هذا الشأن بين الأطراف الثريكة الداخلية والأطراف الثراف الثراف

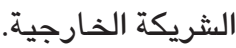

ومجموعة من التدابير العملية الكفيلة في آن واحد بضمان استدامة

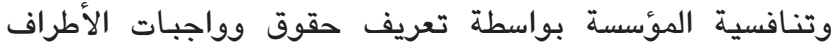

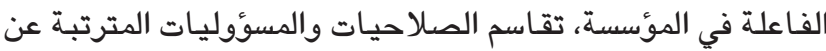

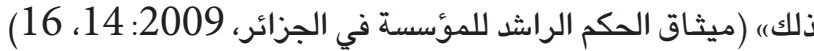

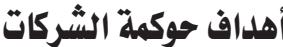

حوكمة الثركات ليست غاية في حد ذاتها. إنها وسيلة لخلق

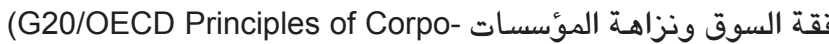
rate Governance, 2015 :3)

تسعى الحوكمة إلى تحقيق رفع كفاءة أداء المؤسسات،

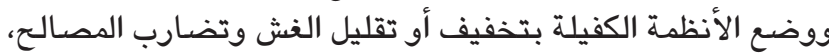

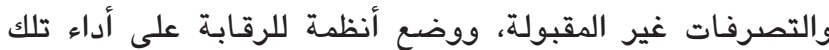

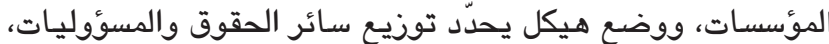

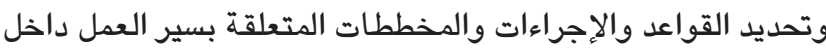

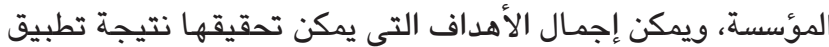
نظم الحوكمة فيما يلي: (دداش امنة، بوزيان عثمان، 2017: 233) - - تحقيق الشفافية والعدالة ومنح الحق في مساءلة إدارة

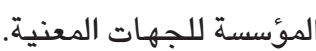

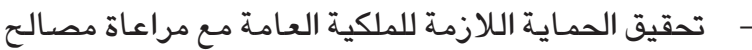

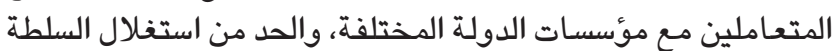
في تفضيل المصلحة العامة.

- - تحقيق فرصة مراجعة الأداء من خارج أعضاء الإدارة

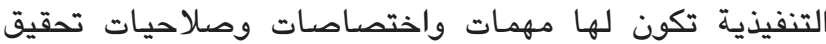

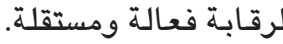

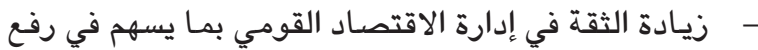

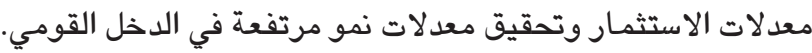

3ـ أهمية حوكمة الشركات

تتجلى أهمية حوكمة الثركات في عديد المزايا والمنافع التي

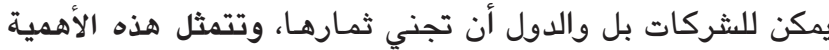

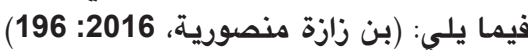
- المساعدة في الحصول على التمويل عن طريق الأسهم، السندات والقروض ويتكلفة أقل. - - ل زيادة جذب الاستثمارات والمؤسسات الأجنبية. - - رفع القيمة السوقية للمؤسسات. - الرفع من مستوى الثقة مع الأطراف المتعاهلة هـع

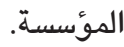
- التقليل من مخاطر الأزمات المالية على مستوى المؤسسة، والاقتصساد بشكل عام.

$$
\text { - - - محاربة الفساد داخل المؤسسة وخارجها. }
$$

\section{4ـ المبادئ الأساسية لحوكمة الشركات وفقا ليثاق حوكمة الشركات} في الجزائر

يعد ميثاق حوكمة الثركات الصادر سنة 2009 إطارا ودليلا إرشاديا يسمح بفهم المبادئ الأساسية للحكم الراشد الثار 
دراسة (المناصير، 2013) بعنوان (أثر تطبيق قواعد حوكمة

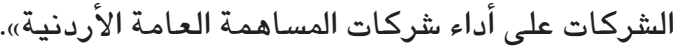

هدفت الدراسة إلى بيان أثر تطبيق قواعد الحوكمة على أداء

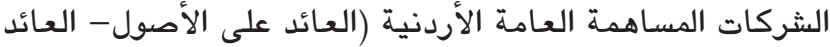

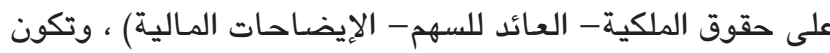

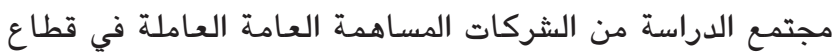

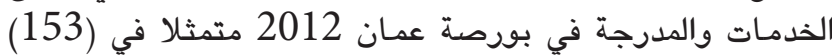

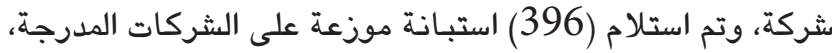

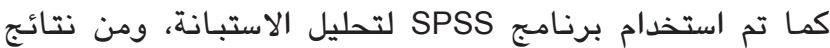

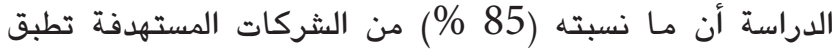

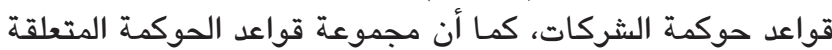

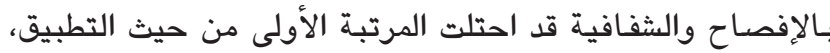

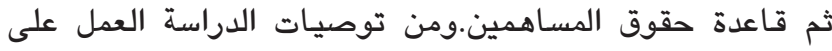

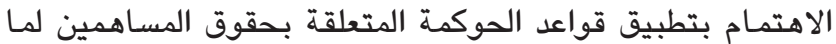

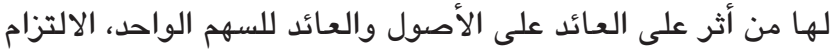

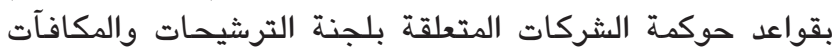

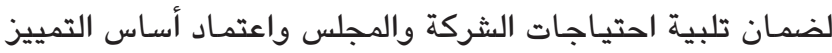
في الأداء لمنح المكافآت. تلنة الفيات

دراسة (Machoki, 2015)

«The effect of corporate governance practices on earnings management of companies listed at the Nairobi securities exchange "

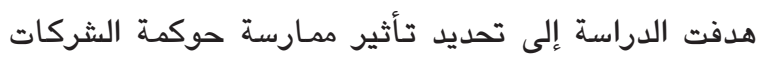

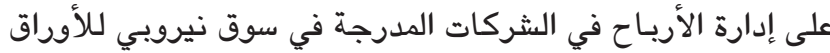

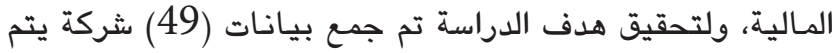
تداولها بشكل مستمر ونشط في سوق نيروي لتي للأوراق المالية خلات

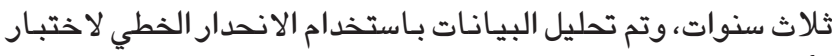

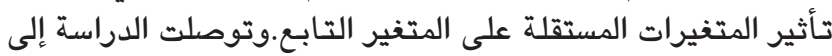

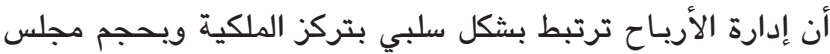

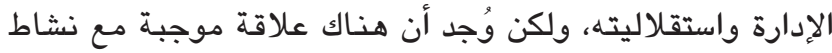

المجلس وازدواجية الرئيس التنفيذي للشركة.

دراسة (صديقي خضرة 2016) بعنوان (ردىى مساهمة ميثاق

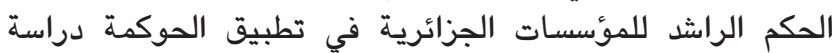
حالة مؤسسة NCA رويبة الجزائر) هدفت هذه الجية الدراسة إلى إبراز

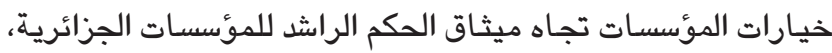

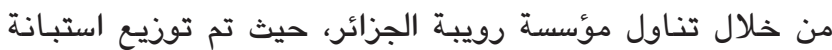

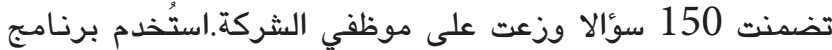
SPSS النتائج، أبرزهـا: أنه ومنذ إطلاق ميثاق الحكم الراشد للمؤسيسات

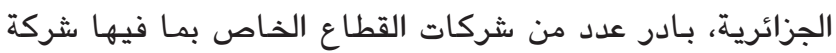

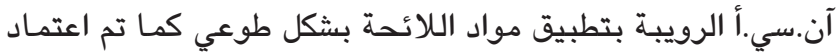

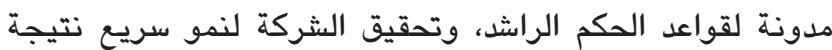

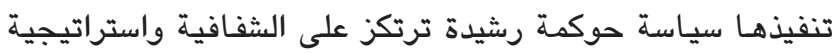
التواصل المنظم مع مختلف أصحاب المصالح بما فيها فيا العائلة.

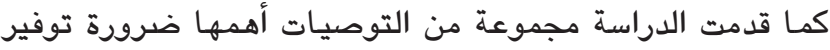

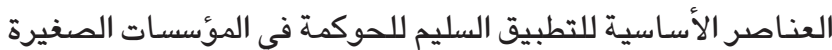

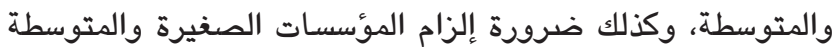

1.5

الأطراف الشريكة الداخلية تتمثل في: مالكي المؤسسة، الأشخاص الذين تم تفويضهم من قبل المالكين لجزء من حقوقهم وصلاحياتهم مثل الإداريين والمسيرين، كل واحد تلون من هؤلاء

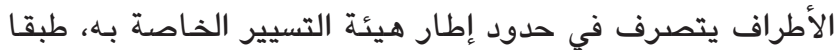

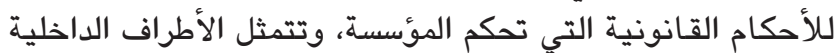
في: (ميثاق الحكم الراشد للمؤسسة في الجزائر، 2009: 60) - -

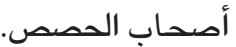

- مجلس الإدارة الذي يجتمع ويتداول فيه الإداريون. - - المديرية العامة المتمثلة في الفريق التنفيذي (المسيرون). 2.5 الأطراف الشريكة الخارجية يتشكل المحيط الخـاص للمؤسسة من أطراف فاعلة، والذين

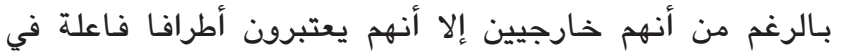

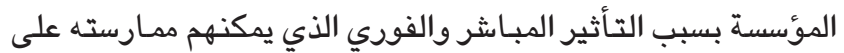

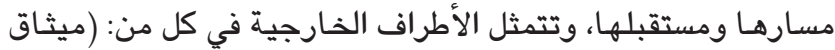

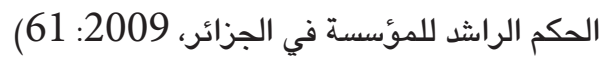

- - الإدارات العمومية: باعتبارهم فروعا للدولة، هم مكلفون بتنفيذ السياسة الاقتصادية بواسطة تطبيق القوانين والتي تنتج

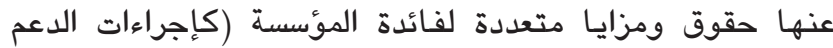

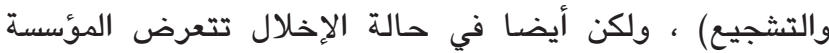

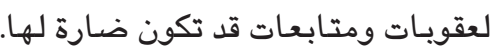

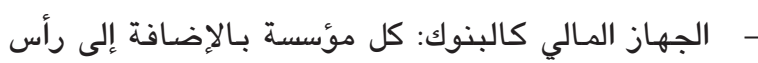

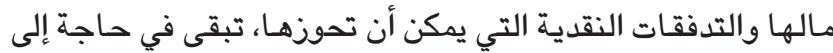

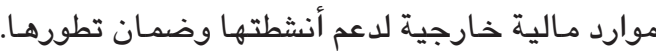

- - الموردون ومقدمو الخدمات: حيث يتعين على كل مؤسسة، لتمويل نفسها، اللجوء إلى الموردين ومقدمي الخدمات.

- - ل الزيائن: في مناخ تنافسي حاد، يمثل زيائن المؤسسة

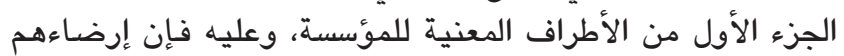
وكسب ولائهم هو الهدف الأساسي.

- - العمال: يعينون من سوق العمل ويريطهم بـالمؤسسة

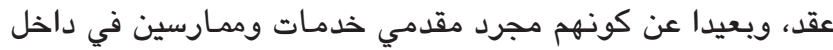

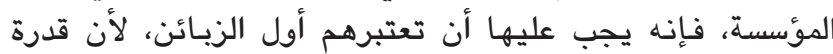
المؤسسة على تحقيق أهدافها تعتمد عليهم إلى حد كبير. - - المنافسون: لا تقتصر المنافسة على التخاصم حول

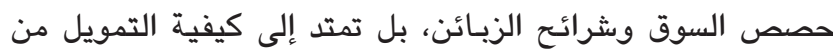
عند الموردين ومقدمي الخدمات، وكذا توظيف الكفاءات التئي التقنية

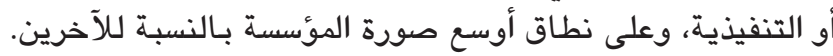

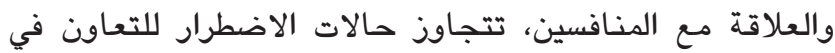

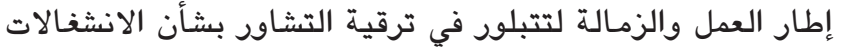
القطاعية المشتركة كالمنافسة غير المثروعة في ترقية الدراسات السابقة: من الدراسات التي تناولت الموضوع نذكر ما يلي: 


\section{ثانيا: الجانب التطبيقي}

مجتمع وعيّنة الدراسة

يتشكل مجتمع الدراسة من مجموع إطارات المؤسسة البالغ

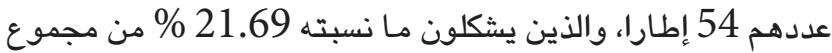

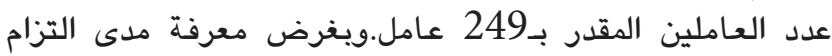

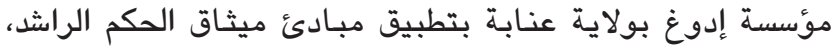
تم اختيار عينة من بين إطارات هذه المؤسسة، على على اعتبار أنها

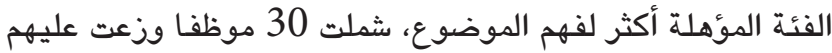

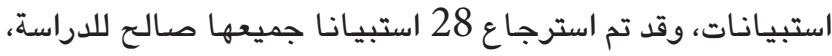

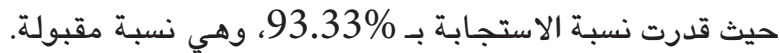

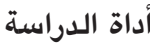

تم الاعتماد في هذه الدراسة على استبيان تم إعداده وفق العقاد العاد

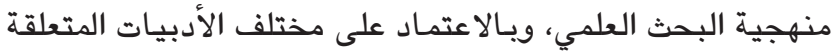
بموضوع الدراسة، قسم الاستبيان إلى جزئين رئيسين:

- الجزء الاول: خصص للمعلومات العامة حيث تضمن 4 أسئلة

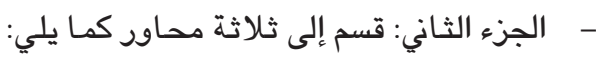

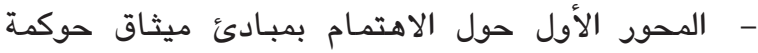

الثركات من قبل مؤسسة إدوغ عنابة، تضمن 4 أسئلة. - المحور الثاني حول تطبيق مبدئي الإنصاف والشفافية في مؤسسة إدوغ عنابة، وقد احتوى 6 أسئلة.

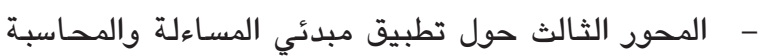
في مؤسسة إدوغ عنابة، وتضمن 7 أسئلة.

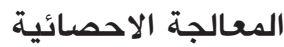

تم الاعتماد على برنامج الحزم الاحصائية للعلوم الاجتماعية

SPSS 20

$$
\begin{array}{r}
\text { - } \\
\text { - }
\end{array}
$$

وتم استخدام مقياس ليكارت الثلاثي لقياس ردود أفراد عينة

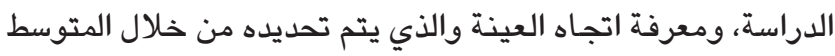

الحسابي كما يلي: (عز عبد الفتاح)

من 1 إلى 1.66 غير موافق (عن عبد القاح

من 1.67 إلى 2.33 من محايد

$$
\text { من } 2.34 \text { إلى } 3 \text { موافق } 1.67 \text { إلى }
$$

قياس ثبات وصدق الاستبيان

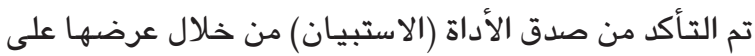

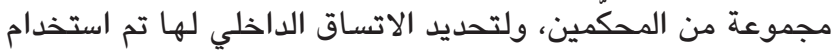

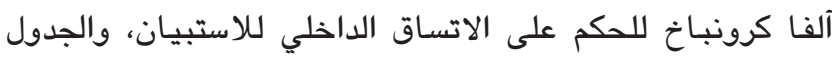
الآتي يوضح قيّم آلفا كرونباخ التي تم التوصل إليها.
بنشر تقرير سنوي مها يسمح بالتواصل الواضح والفعال. دراسة (بن شهيدة فضيلة ورمضاني محمد 2017) بعنوان

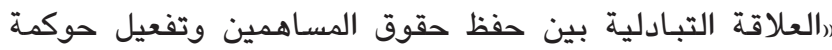

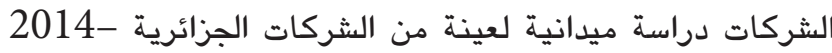

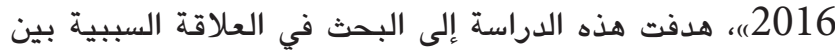
حقوق المساهمين وتفعيل حوكمة الثركات، حيث تم الثمالئ استخدام

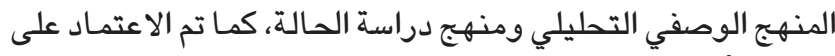

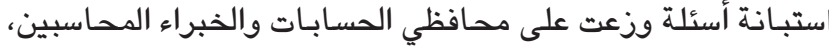

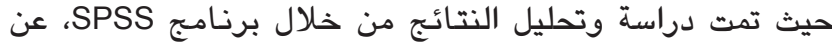

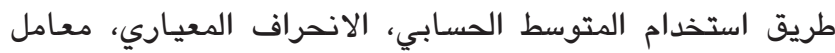

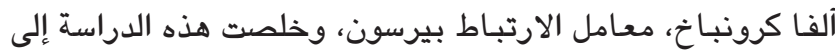

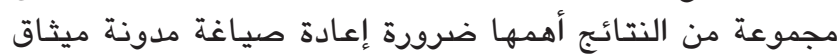

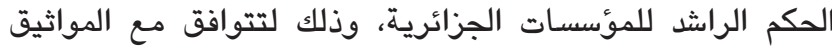

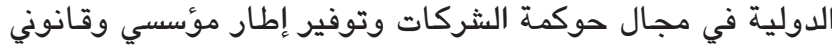

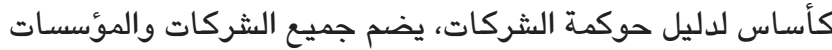

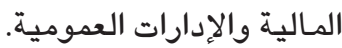

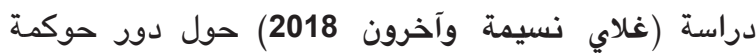
الشركات في الرفع من كفاءة مؤسسات الأعمال الجزائرية (دراسة دراسة

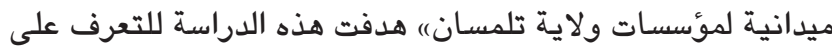

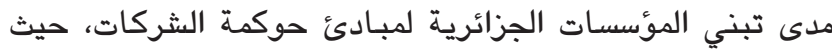

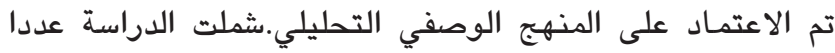

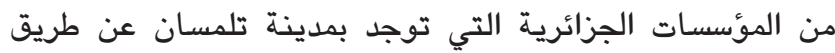

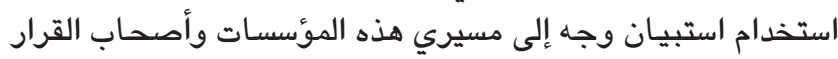

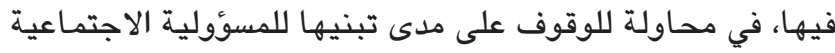

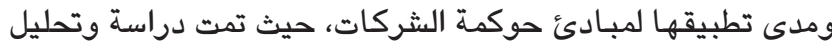

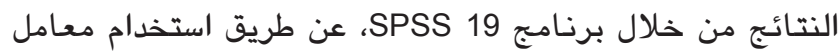

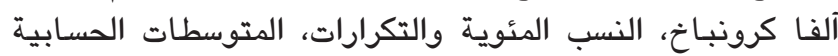

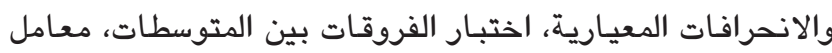

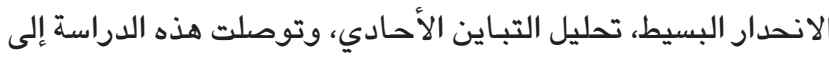
أن المؤسسات الجزائرية لا تطبق مبادئ حوكمة الشركات.

ما يميز هذه الدراسة عن غيرها من الدراسات السابقة:

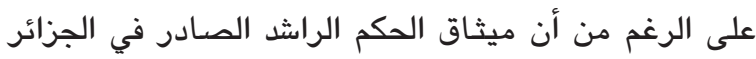

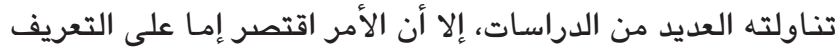

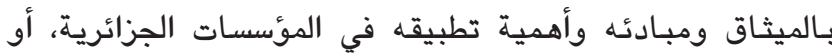

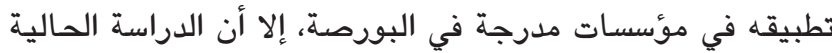

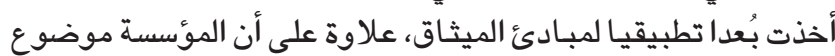

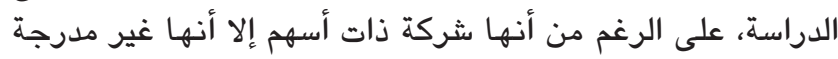

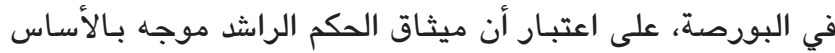

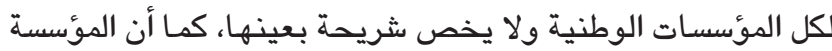

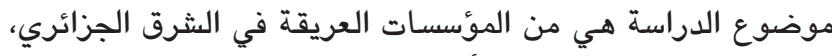

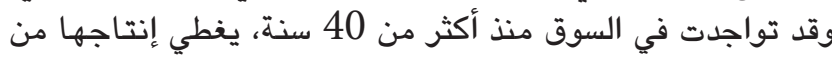

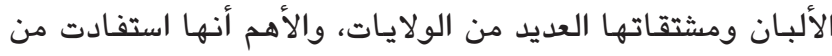

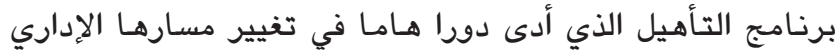

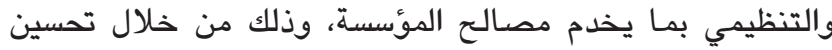

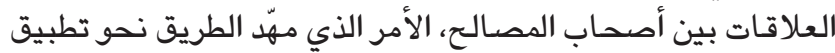

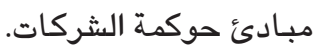




\begin{tabular}{ccc}
\hline إدارة أعمال & \\
\hline $32.14 \%$ & 09 & التخصصرار \\
$28.57 \%$ & 08 & النصصسات \\
\hline
\end{tabular}

المصدر : من إعداد الباحثين بالاعتماد على إجابات عيّنة الدراسة

الجدول رقم (3) يشير إلى أن تخصص إدارة أندارة أعمال هو

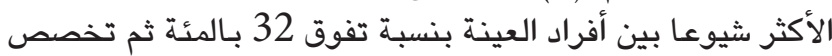

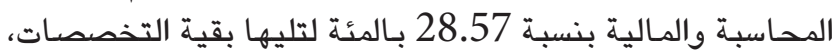

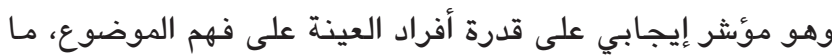
يضفي مصداقية أكثر على النتائج المتحصل علئ آليها. رال الخبرة الههنية: يوضح الجدول التالي توزيع أفراد عيّنة الدراسة حسب خبرتهم المهنية

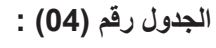

توزيع عينة الاراسة حسب الخبرة المهنية

\begin{tabular}{|c|c|c|}
\hline النسبة & 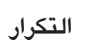 & الخبرة المهنية \\
\hline $42.86 \%$ & 12 & أقل من 5 سنوات \\
\hline $57.14 \%$ & 16 & من 5 إلى 15 سنة \\
\hline $0 \%$ & 00 & أكثر من 15 سنة \\
\hline
\end{tabular}

المصدر: من إعداد الباحثين بالاعتماد على إجابات عينة الدراسة

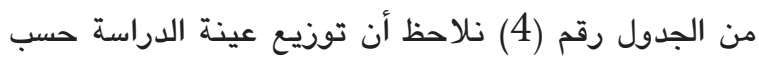

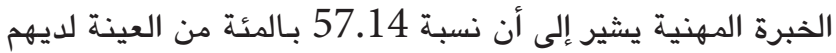

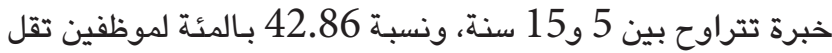
خبرتهم عن 5 سنوات، وهذا يشكل بدوره عاملا ونا إيجابيا يدعم الثقة في المعلومات المتحصل عليها.

\section{ثانيا: تخليل تتائج محاور الدراسة} • تحليل نتائج الدحور الأول: يوضح الجدول الموالي

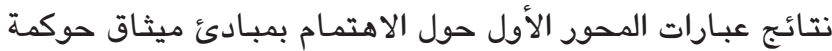
الشركات من قبل مؤسسة إدوغ عنابة:

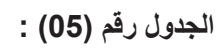

\begin{tabular}{|c|c|c|c|c|}
\hline 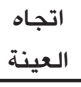 & المعياري & الحسابي & العبارة & الرقم \\
\hline موافق & 0.79266 & 2.4643 & أنتم على دراية بما جاء به ميثاق & 01 \\
\hline موافق & 0.73733 & 2.6071 & تولي المؤسسة أهمية لمفهوم & 02 \\
\hline موافق & 0.74536 & 2.5000 & يوجد في المؤسسة دليل مكتوب & 03 \\
\hline موافق & 0.78595 & 2.3929 & 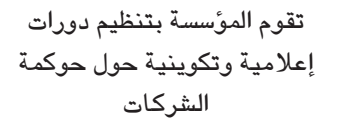 & 04 \\
\hline موافق & 0.55894 & 2.4911 & المحور ككل & \\
\hline
\end{tabular}

نتائج عبارات المحور الأول

\begin{tabular}{|c|c|}
\hline آلفا كرونباخ & المحاور \\
\hline 0.708 & المحور الأول \\
\hline 0.618 & المحور الثاني \\
\hline 0.608 & المحور الثالث \\
\hline 0.742 & جميع عبارات الاستبيان \\
\hline
\end{tabular}

SPSS 20 المصدر : من إعداد الباحثين بالاعتماد على مخرجات
SPSS 20 المصدر: من إعداد الباحثين بالاعتماد على مخرجات

من الجدول (1) أعلاه يتضح أن قيمة آلفا كرونباخ بالنسبة

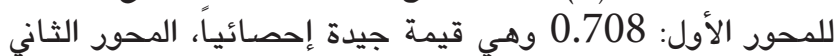

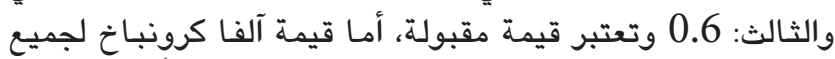

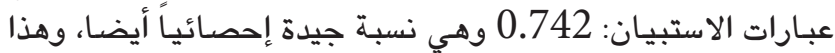
يدل على أن عبارات الاستبيان تتمتع بالاتساق الداخلي والثبات.

\section{تخليل النتائج ومناقشتها}

أولا: الوصف الإحصائي لعيّنة الدراسة حسب المعلومات العامة

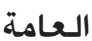

• المؤهل العلمي: يوضح الجدول التالي توزيع أفراد عينة الدراسة حسب مؤهلهم العلمي العلي يوفي

\begin{tabular}{|c|c|c|}
\hline النسبة & الت التكرار & المؤهل العلمي \\
\hline $64.29 \%$ & 18 & ليسانس \\
\hline $35.71 \%$ & 10 & ماجستير/ ماستر \\
\hline $0 \%$ & 00 & دكتوراه \\
\hline $0 \%$ & 00 & شهادة مهنية أخرى \\
\hline
\end{tabular}

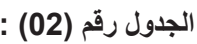

المصدر : من إعداد الباحثين بالاعتماد على إجابات عينة الدراسة

من الجدول (2) يتضح أن المؤهل العلمي لعينة الدراسة

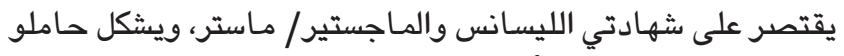

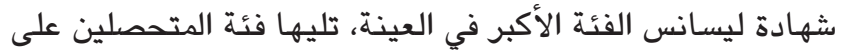

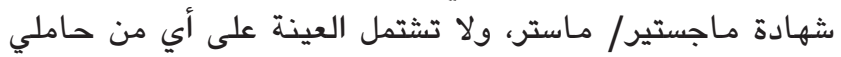
شهادة دكتوراه أو شهادة مهنية أخرى. " التخصص: يوضح الجدول التالي توزيع أفراد عيّنة الدراسة حسب التخصص

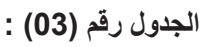

\begin{tabular}{ccc}
\multicolumn{3}{c}{ توزيع عينة الدراسة حسب التخصص رقم 203} \\
\hline اقتصاد
\end{tabular}




\begin{tabular}{|c|c|c|c|c|}
\hline العينة & المعياري & الحسابي & العبارة & الرقم \\
\hline موافق & 0.87891 & 2.4286 & يوجد الفصل بين الوظائف على & 02 \\
\hline موافق & 0.73102 & 2.6429 & بالرقابة عن طويسة بشكل دوري مختف & 03 \\
\hline موافق & 0.58531 & 2.7500 & 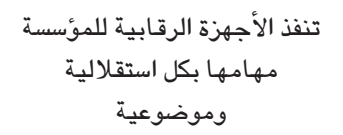 & 04 \\
\hline موافق & 0.74447 & 2.5357 & الأجهزة الرقابية للشثركة ترى بـأن & 05 \\
\hline موافق & 0.68526 & 2.6071 & 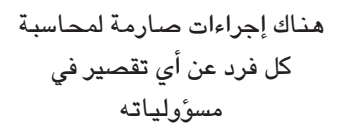 & 06 \\
\hline غير موافق & 0.78004 & 1.6429 & هناك تمييز في محاسبة الأفراد & 07 \\
\hline موافق & 0.41148 & 2.4286 & الهحور ككل & \\
\hline
\end{tabular}

SPSS 20 المصدر: من إعداد الباحثين بالاعتماد على مخرجات

في الجدول رقم (7) يتضح أن المتوسط الحسابي للمحور ككل يساوي 2.42 وهو في المجال 2.34 إلى 3 والذي يجعل اتجاه عينة

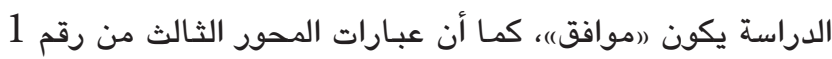
إلى 6 اتجاه العينة بها (روافق)، والعبارة رقم 7 اتجاه العينة

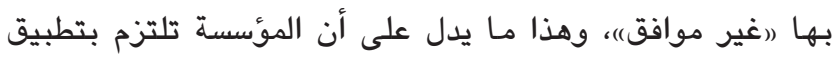

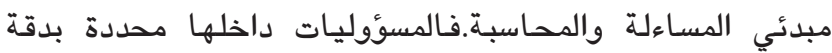

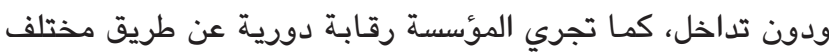

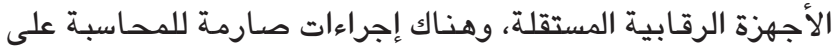
أي تقصير.

\section{ختبار فرضيات اللدراسة}

T- تم اختبار فرضيات الدراسة عن طريق إجراء اختبار Test

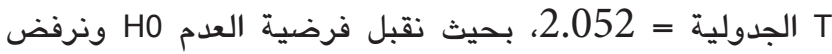
الفرضية البديلة H1 إذا كانت قيمة T المحسوبة أقل من T الجدولية،

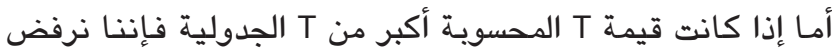
فرضية العدم H0 ونقبل الفرضية البديلة H1

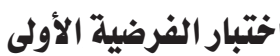

HO لا تهتم مؤسسة إدوغ عنابة بمبادئ ميثاق حوكمة الشركات

H1 تهتم مؤسسة إدوغ عنابة بمبادئ ميثاق حوكمة الشركات
يتضح من الجدول (5) أن المتوسط الصسابي للمحور ككل يساوي 2.49 وهو في المجال 2.34 إلى 3 والذي يجعل اتجاه عينة الدراسة يكون (هوافق)،، كما أن جميع عبارات المحور الأول اتجاه

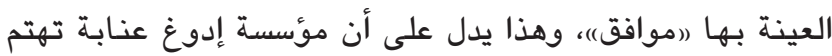
بمبادئ ميثاق حوكمة الثركات، ويُستدل على هذا الأمر بتوفيرهـا لدليل مكتوب حول حوكمة الثركات وتنظيمها لدورات تكوينية تحاول من خلالها جعل الحوكمة ثقافة سائدة في المؤسسة. • تحليل نتائج المحور الثاني: الجدول التالي يُظهر نتائج عبارات المحور الثاني حول تطبيق مبدئي الإنصاف والشفافية في

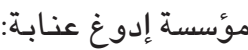

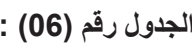

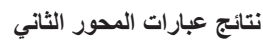

\begin{tabular}{|c|c|c|c|c|}
\hline العينة & المعياري & الحسابي & العبارة & 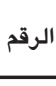 \\
\hline موافق & 0.74180 & 2.5714 & تتوافر المعلومات الكافية وفي الوقت & 01 \\
\hline موافق & 0.74180 & 2.5714 & 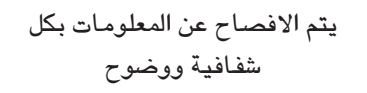 & 02 \\
\hline موافق & 0.78004 & 2.3571 & توجد إجراءات مكتوية تحدد & 03 \\
\hline موافق & 0.79349 & 2.5000 & في الوقتى الميحاسب أعضاء مجلس الإدارة الملوات حول & 04 \\
\hline موافق & 0.56811 & 2.7857 & أجور الإداريين محددة بدقة & 05 \\
\hline موافق & 0.61183 & 2.6786 & توزيع المكافآت والتعويضات يتم & 06 \\
\hline موافق & 0.41693 & 2.5774 & الهحور ككل & \\
\hline
\end{tabular}

SPSS 20 الهصدر: من إعداد الباحثين بالاعتماد على مخرجات

يُظهر الجدول (6) أن المتوسط الحسابي للمحور ككل يساوي

2.57 وهـو في المجال 2.34 إلى 3 والذي يجعل اتجاه عينة الدراسة الدية يكون ((موافق)، كما أن جميع عبارات المحور الثاني اتجـاه العينة

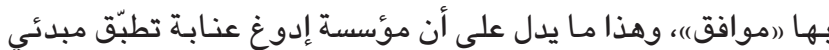

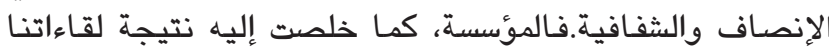

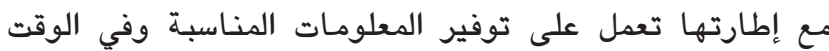

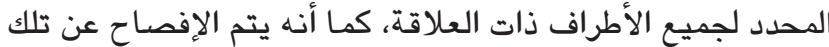

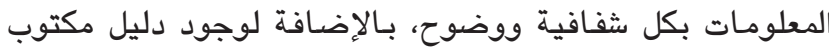

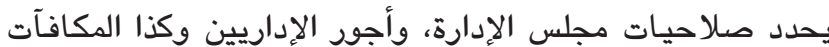
والتعويضـات التي تُصرف بطريقة عادلة.

• تحليل نتائج المحور الثالث: الجدول الآتي يظهر نتائج

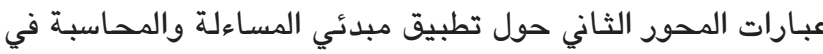

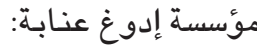

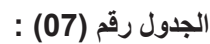

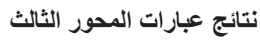

\begin{tabular}{ccccc}
\hline الرقم & & \\
& 01 & & \\
\end{tabular}


مع عمال المؤسسة أن كل عامل لديه مسؤوليات محددة ولا يتدخل

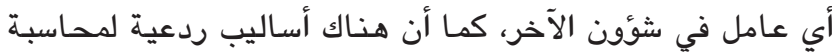

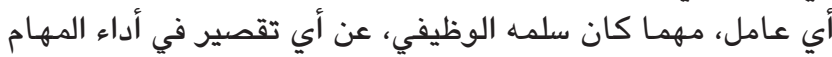
المنوطة إليه. - - اليه.

\section{اختبار الفرضية الرئيسية}

HO الشركات

H1 تطبق مؤسسة إدوغ عنابة مبادئ ميثاق حوكمة

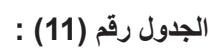
الشركات

\begin{tabular}{|c|c|c|c|}
\hline القرار & Sig & T الجدولية & T المحسوبة \\
\hline نرفض H0 & 0.000 & 2.052 & 69.648 \\
\hline
\end{tabular}

SPSS 20 المصدر: من إعداد الباحثين بالاعتماد على مخرجات

t بما أن t t المحسوية = 69.648 وهي أكبر من قيمة

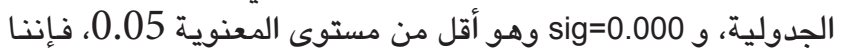

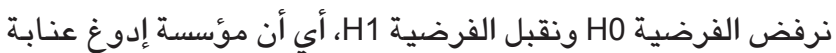
تطبق مبادئ ميثاق حوكمة الشركات، حيث أكدت إجابـات عمال مونال

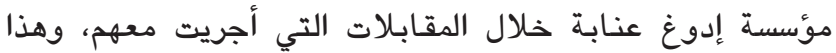

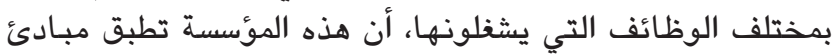
ميثاق حوكمة الشركات.

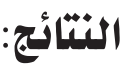

\section{من أهم النتائج المتوصل إليها:}

1. كان لعملية التأهيل التي شهدتها المؤسسة الأثر الإيجابي إنها في تبنيها لمبادئ الحوكمة.

2. تهتم مؤسسة إدوغ عنابة بمبادئ ميثاق حوكمة الشركات

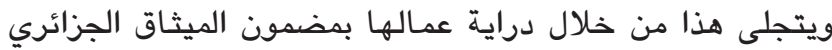

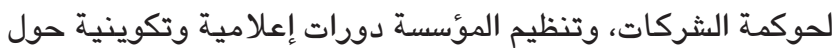
حوكمة الشركات.

3. يوجد على مستوى مؤسسة إدوغ عنابة دليل مكتوب حول

حوكمة الثركات يتوافق مع خصوصية المؤسسة.

4. تطبق مؤسسة إدوغ عنابة مبدئي الإنصاف والشفافية،

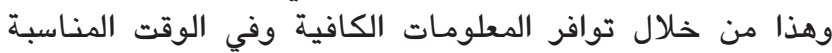

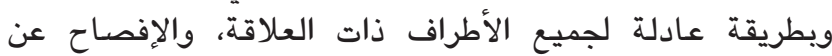

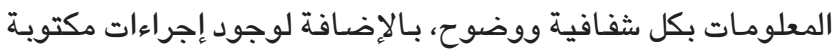

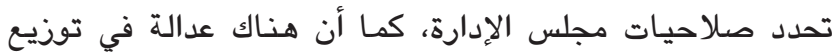
المكافآت والتعويضـات داخل المؤسسة.

5. تطبق مؤسسة إدوغ عنابة مبدئي المساءلة والمحاسبة،

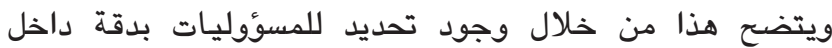

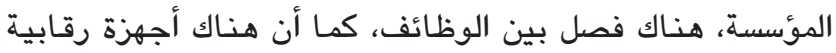

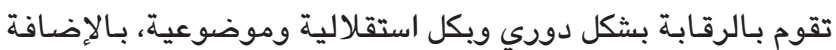

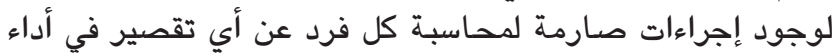

مهامه، وهذا دون تمييز.

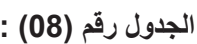

نتائج اختبار T- Test للعينة الواحدة للفرضية الأولى

\begin{tabular}{cccc}
\hline الجدولية T & Sig & المحسوبة T \\
\hline H0 نرفض & 0.000 & 2.052 & 23.583 \\
\hline
\end{tabular}

المصدر: من إعداد الباحثين بالاعتماد على مخرجات SPSS 20

بما أن t المحسوية = 23.583 وهي أكبر من قيمة الجدولية، وsig=0.000 وهو أقل من مستوى المعنوية 0.05، فإنتا

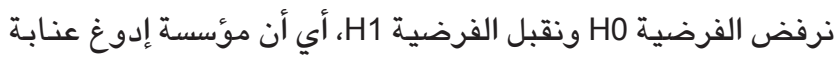

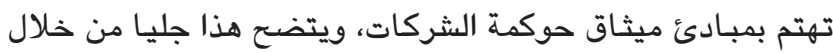

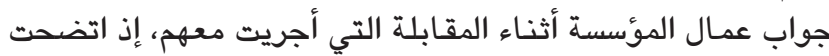

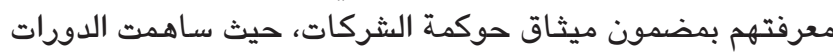

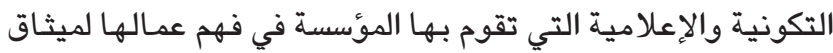

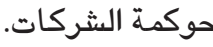

\section{اختبار الفرضية الثانية}

H0 H1 تطبق مؤسسة إدوغ عنابة مبدئي الإنصاف والشفافية

$$
\text { الجدول رقم (09) : الجمان }
$$

نتائج اختبار T- Test للعينة الواحدة للفرضية الثانية

\begin{tabular}{cccc}
\hline الجدولية T & المحسوبة T \\
\hline H0 Sig & 0.000 & 2.052 & 32.711 \\
\hline
\end{tabular}

SPSS 20 المصدر: من إعداد الباحثين بالاعتماد على مخرجات

بما أن t المحسوية = 32.711 وهي أكبر من قيمة

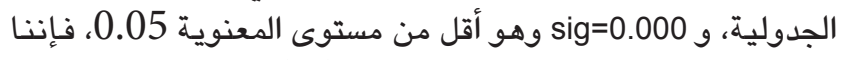

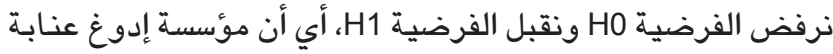

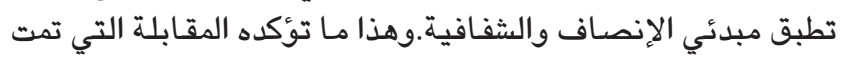

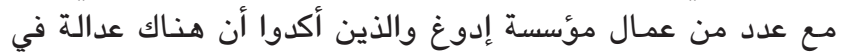

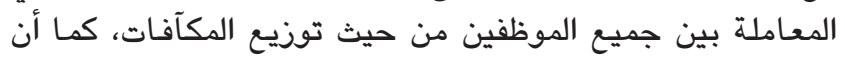
المعلومات متوافرة للجميع دون تمييز.

\section{اختبار الفرضية الثالثة}

H0 H1 تطبق مؤسسة إدوغ عنابة مبدئي المساءلة والمحاسبة

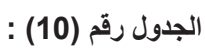

نتائج اختبار T- Test للعينة الواحدة للفرضية الثالثة

\begin{tabular}{cccc}
\hline الجدولية T & Sig & الحسرو T \\
\hline H0 نرفض & 0.000 & 2.052 & 31.231 \\
\hline
\end{tabular}

SPSS المصدر: من إعداد الباحثين بالاعتماد على مخرجات 20

بما أن t الهحسوية = 31.231 وهي أكبر من قيمة الجدولية، و sig=0.000 وهو أقل من مستوى المعنوية 0.05، فإنتا

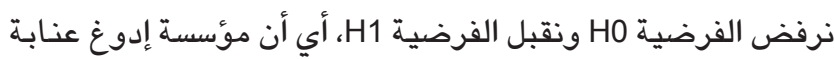

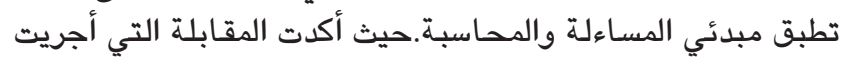


الحوكمة ورفع جودة التدقيق في المؤسسة، المجلة الجزائرية للاقتصاد

$$
\text { والمالية، العدد } 3 .
$$

داود خيرة. (2016) ـ أثر قياس مستوى تطبيق الحوكمة في عينة من المؤسسات الجزائرية، مجلة الاقتصاد والتنمية، العدد6.

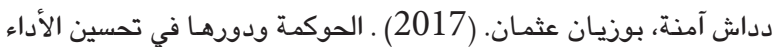
التنافسي للمؤسسات الاقتصادية، مجلة المالية والأسواق، العدد 6. 9. صديقي خضرة. (2016) ـ مدى مساهمة ميثاق الحكم الراشد للمؤسسات

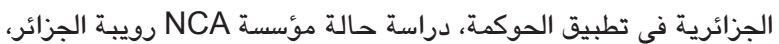
مجلة البشائر الاقتصادية، العدد 7.

10. عز عبد الفتاح، مقدمة في الإحصاء الوصفي والاستدلالي باستخدام SPSS متوفر على الموقع:

http:// site. iugaza. edu. ps/ mbarbakh/ files/ 2010/ 02/ .11 questionaire_analyzis. pdf

12. غلاي نسيمة وآخرون. (2018) ـ دور حوكمة الشركات في الرفع من كفاءة

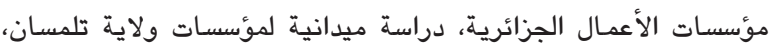
مجلة المالية والأسواق، العدد 8.

13. ميثاق الحكم الراشد للمؤسسة في الجزائر، 2009، متوفر على الموقع:

http:// www. ecgi. org/ codes/ documents/ code_alge- .14 ria_2009_ar. pdf

15. يحياوي إلهام، بوحديد ليلى. (2014) . الحوكمة ودورهـا في تحسين الأداء

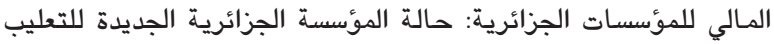
بالرويبة، مجلة أداء المؤسسات الجزائرية، العدد 5.

ثانيا المراجع الأجنبية

1. Abdelkader Rachedi, Mohamed Maarif, Mohamed Benhamida,)2014(. Les modèles de la gouvernance d'entreprise. Les cahiers du MECAS. $N^{\circ} 10$.

2. Belabdelli Abdallah. (2017). Le rôle de la gouvernance d'entreprise a la Valorisation de l'information afin d'adopter une stratégie. Revue de recherche et d'études juridiques et politiques. Vol $6 . N^{\circ} 2$.

3. Boussadia Hichem. (2014). La gouvernance d'entreprise et le contrôle du dirigeant : cas de l'entreprise publique Algérienne. Thèse de Doctorat. Université Abou Bekr Belkaid. Tlemcen. L'Algérie

4. Code algérien de gouvernance d'entreprise. (2009). CARE.

5. Frédéric Bernard, Rémi Gayraud, Laurent Rousseau. (2013). Contrôle interne, Maxima laurent du mesnil éditeur, 4e éditions. Paris, France.

6. G20/OECD Principles of Corporate Governance. (2015). OECD.

7. Iraya, c. Mwangi, m.\&Muchoki, g.w. (2015). The effect of corporate governance practices on earnings management of companies listed at the Nairobi securities exchange, European scientific journal. Vol.11. $N^{\circ} .1$.

8. Messahel Sassia. (2017). La gouvernance d'entreprises en difficultés en Algérie : Quel rôle pour les Commissaires aux comptes? Revue des sciences économiques et de gestion. $N^{\circ}$ 17.

9. Meziani Henen. Chelil Abdellatif.(2014). Les mécanismes de contrôle dans la gouvernance d'entreprise en Algérie(le cas de l'entreprise starr tlemcen).Revue économique Al Bashaer. $N^{\circ} 01$

10. Rich Hayes, Roger Dassen, Arnold Schilder, Philip Wallage. (2005). Principles of auditing an introduction to international standards on auditing, Pearson education limited, second edition. England.

\section{الخاتمة:}

سعت هذه الدراسة لمعرفة واقع تطبيق مبادئ ميثاق حوكمة

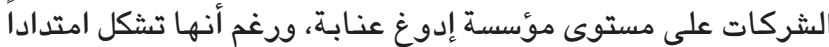

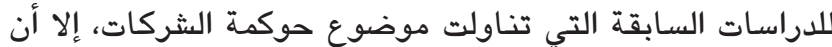

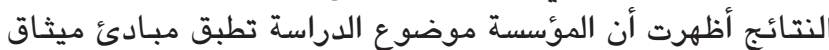

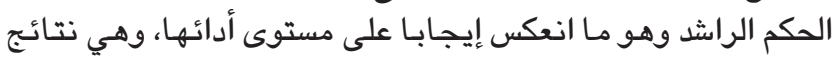

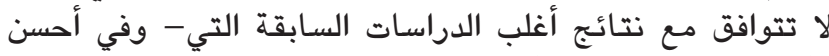

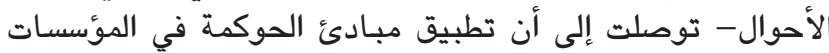

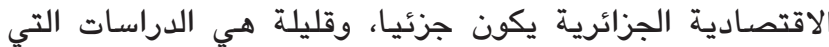

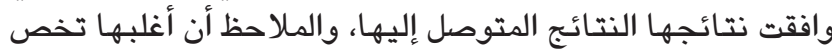

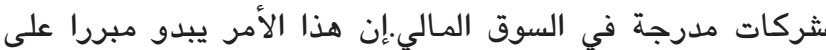
اعتبار أن موضوع حوكمة الشركات في الجزائر حديث النئ النشأة

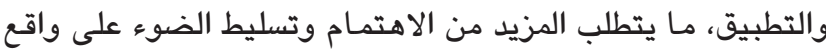

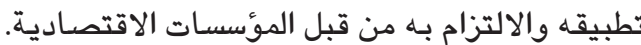

التوصيات:

1. توصي الدراسة بخرورة مواصلة مؤسسة إدوغ عنابة لجهودهـا في مجال إرساء وتعزيز مبـادئ الحوكمة.

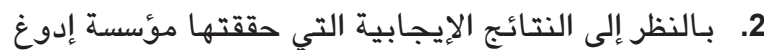

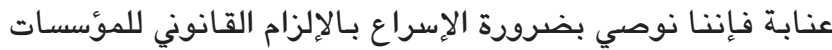

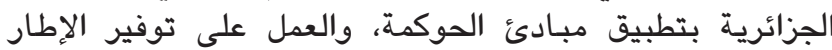

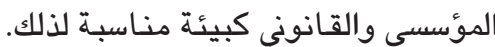

3. إجراء المزيد من الدراسات والبحوث حول حوكمة المؤسسات لتعميق وفهم أهميتها.

4. ضرورة تعميم برامج التأهيل على المؤسسات الجزائريـة كخطوة ضرورية لتمكينها من تبني مبادئ الحكم الراشد.

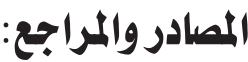

أولاـ المراجع العربية

1. أحمد مداني، مداح عبد الهادي، (2016) ـ مدى تطبيق مبادئ حوكمة

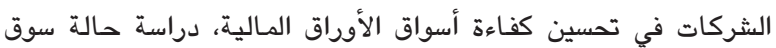

الإمارات للأوراق المالية، مجلة الاقتصاد والهات المالية الية، المجلد 2، العدد 1. 2. المناصير، عمر (2013) ، أثر تطبيق قواعد حوكمة الثركات على أداء

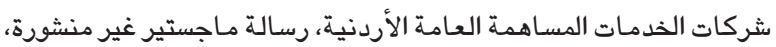

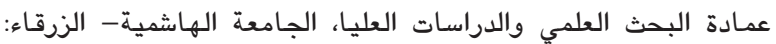
الأردن بروش زين الدين، دهيمي جابر. (2012) . دور آليات الحوكمة في الحد

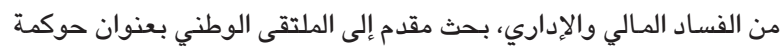

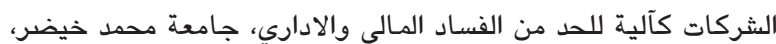

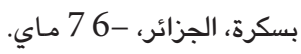

بن زازة منصورية. (2016) ـ التدقيق المحاسبي ودوره في إرساء مفهوم الحوكمة في ظل قانون SOX، مجلة دفرة دفاتر بوادكس، العدد 5.

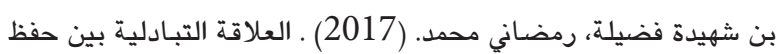

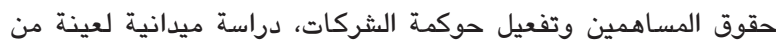

الثركات الجزائرية 2014 - 2016، مجلة دفاتر بوادكس، العدد 7. بوفاسة سليمان، سعيداني الرشيد. (2015) ـ لجنة التدقيق كمدخل لتفعيل 